\title{
Desventuras Químicas
}

\author{
Lição plenária proferida no XVIII Encontro Nacional da SPQ, Universidade de \\ Aveiro, 25-27 Março 2002
}

JORGE C. G. CALADO*

\section{Introdução}

O título, Desventuras Químicas, pode parecer uma provocação num Encontro dedicado à Aventura da Química. Deriva, todavia, da convicção de que a verdadeira atitude científica está, "à rebours", no remar contra a maré. Não se progride confirmando a teoria, mas sim mostrando que ela está errada. 0 genuíno critério científico é - uso um neologismo - a "falseabilidade", isto é, a possibilidade de provar que algo é falso. Por outro lado, é preciso não esquecer que o erro pode ser portador de muitas verdades. $\mathrm{O}$ exemplo clássico é dizer que "Hoje é 5. ${ }^{a}$ Feira". (Não é, é 4. ${ }^{a}$ Feira!) Mas segue-se daí que não é $6{ }^{a}$, nem Sábado, nem Domingo, nem 2. ${ }^{a}$, nem 3. ${ }^{a}$ Feira, que são todas afirmações certas. Cinco conclusões certas para uma errada é, nesta época de sondagens e conhecimento probabilístico, bastante razoável.

Percebe-se que, do ponto de vista pedagógico, é atraente pintar a química como a ciência de todas as aventuras. Serve, entre outras coisas, para atrair estudantes. Mas será que isso funciona? Duvido... No news is good news, diz o ditado. Julgo, todavia que o (quase) converso é que é verdadeiro: Good news is not news, como se vê quotidianamente nos telejornais (já ninguém lê jornais e poucos ouvem rádio). 0 crime e a desgraça são o que está a dar. Ora talvez a 'desventura' sirva também para "vender" a química, isto é, seja uma forma mais eficaz de fazer o marketing da química (tanto junto dos estudantes como dos políticos; e também - porque não? junto dos candicatos a professores).

É apropriado falar de desventura no que respeita à química, tanto mais que o seu fundador, Lavoisier, foi uma das vitimas dos excessos da Revolução Francesa a mesma que nos deu a Liberdade, a Igualdade e a Fraternidade. Houve ainda, ao longo dos tempos, casos de censura, tentativas de controle pelo poder politico, etc que coarctaram a criatividade dos químicos, atrasando o desenvolvimento da ciência. Noutros casos, cientistas triunfaram apesar de obstáculos terriveis, desde deficiências físicas à passagem por campos de concentração. E é preciso não esquecer que, para uma boa parte da comunidade, a desventura maior era ter nascido mulher. A mulher estava vedado o acesso à universidade e portanto a carreira científica (embora Mme Lavoisier tenha sabido superar tais obstáculos com outros predicados). É dum pouco disto tudo que esta palestra trata. Espera-se que os exemplos sejam isso mesmo exemplares.

\section{Antecedentes}

Toda a gente sabe que a química levou tempo a afirmar-se como ciência independente. A física nasceu na noite estrelada de 9 de Dezembro de 1609, no momento em que Galileo Galilei apontou o seu telescópio à Lua; a química veio à luz mais de 160 anos depois (o dia exacto não está determinado). Depois da Alquimia (séculos IV-XVI), preocupada com o enobrecimento dos me- tais, que durou quase doze séculos, veio a latroquímica (séculos XVI e XVII), considerada como mero auxiliar da medicina. São exemplos maiores de iatroquímicos Paracelso (c. 1490-1541) e Jan Baptista Van Helmont (1577-1644).

Paracelso teve uma vida errante e agitada e veio a morrer em Salzburgo em resultado duma bebedeira debochada ou talvez por ter sido atirado para uma ribanceira por médicos e boticários invejosos. O túmulo está junto ao claustro da Igreja de São Sebastião, no sopé do Kapuzinerberg - Fig. 1. (No mesmo cemitério estão sepultados alguns parentes chegados de Mozart, como o pai, Leopold, e a mulher, Konstanze.) Diga-se, de passagem, que Arthur Schnitzler (1862-1931) dedicou uma das suas peças ao famoso iatroquímico. Em "Paracelsus" (1899), o protagonista é visto como um praticante do hipnotismo terapêutico, interessado na interpretação dos sonhos e, como tal, antecessor de certas figuras cimeiras do modernismo científico como Sigmund Freud (18561939). O seu cepticismo está, porém, mais próximo do relativismo moral de filósofos como o físico Ernst Mach (18381916). Para o Paracelso de Schnitzler não há verdade nem absolutos. As suas últimas palavras na peça são: "Sonhar e acordar, verdade e mentira misturamse. Não há certezas. Nada sabemos a respeito dos outros ou de nós próprios. Estamos sempre a jogar. Sábio é o homem que sabe isto."

Quanto a Van Helmont, de Bruxelas, descobriu a existência dos gases (inventou o nome, que vem do grego, $\chi \alpha_{0} \zeta$, 
ou caos), identificou o dióxido de carbono (a que poeticamente chamou gás ou "espírito silvestre"). Era um cientista no limiar da modernidade: por um lado, perseguia a pedra filosofal e acreditava no poder do sobrenatural; por outro, conhecia a filosofia experimental de Francis Bacon (1561-1626) e deixou-se influenciar pelas descobertas de Harvey e Galileo. Viveu numa das épocas de ouro das ciências e artes europeias, uma época em que coexistiram, além de Harvey (que descobriu a circulação do sangue) e Galileo, génios tão díspares como Napier, Kepler, Shakespeare, Rubens. (Descartes, Milton e Boyle pertenceriam à geração seguinte.)

0 que atrasou a emergência daquilo que seria a química moderna foi o desconhecimento desses fluidos elásticos e subtis que são os gases, e a sua confusão com o ar. Van Helmont começou, Robert Boyle (1627-1691) continuou e Joseph Black (1728-1799) já distinguia os gases uns dos outros. Mas foram verdadeiramente o abastado aristocrata Henry Cavendish (1731-1810), o pastor dissidente Joseph Priestley (17331804) e o boticário Carl Scheele (17421786) que prepararam e identificaram vários gases - hidrogénio, oxigénio, cloro, amoníaco, óxidos de azoto, dióxido de enxofre, monóxido de carbono, metano, fluoreto de hidrogénio, etc (com outros nomes, claro).

O conhecimento da diversidade do estado gasoso era essencial para o entendimento dessa reacção primária que é a verdadeira semente da química: a combustão ou oxidação. Em certo sentido pode dizer-se que o primeiro químico foi o titã Prometeu, e que a civilização começou com a química - uma proto-química - a descoberta do fogo. Vejam, porém, o que aconteceu a Prometeu por ter roubado o fogo aos deuses: acorrentado a um rochedo no Cáucaso, com um abutre (ou águia) a roer-Ihe o figado que diariamente se renovava - a desventura do primeiro químico! (Mais tarde, Hércules convenceu Zeus a libertar Prometeu, mas este teve de usar um anel de metal para sempre, em sinal do seu agrilhoamento. É esta a origem dos aneis!) Mas o fogo - simbolizado por um dos sólidos platónicos, o tetraedro vinha dos gregos. Era, com a terra, a água e o ar, um dos quatro elementos. A química moderna nasce com a descoberta do oxigénio. (A confusão dualista fogo-oxigénio, tem um paralelo na física óptica com a dualidade cor-luz. É a teoria da luz que explica a côr, e não o inverso; Newton estava certo, Goethe estava errado.)

\section{Os oxigénios}

A descoberta do oxigénio, que está na origem da química moderna, foi um dos vários casos (comuns em ciência) de descoberta simultânea e despontou em três sítios: em Inglaterra, por decomposição do zarcão $\mathrm{Pb}_{3} \mathrm{O}_{4}$ graças à acção duma faísca eléctrica, ou separando o óxido mercúrico HgO (Joseph Priestley, 1774); na Suécia, também por calcina-

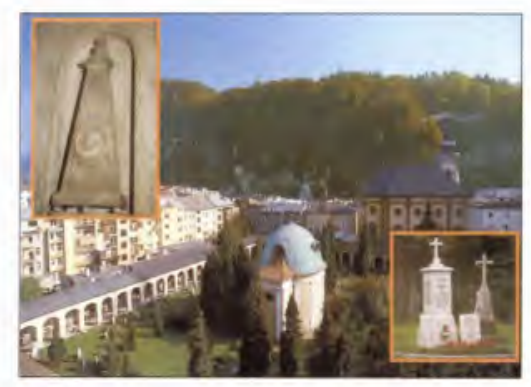

figura. 1 Igreja de São Sebastiào, Salzburgo, com os túmulos de Paracelso (esquerda) e da Familia Mozart (direita)

ção do óxido mercúrico ou por reacção do ácido sulfúrico com óxido de manganês, $\mathrm{MnO}_{2}$ (Carl Wilhelm Scheele, 1771); e em França, por Antoine Laurent Lavoisier (1743-1794). É por isso difícil estabelecer, com exactidão, a data de nascimento da química moderna. Repare-se, todavia, no papel que um composto de mercúrio teve na descoberta. A "prata movediça" dos alquimistas, facilmente oxidada para dar o vermelho "mercurius calcinatus" dos iatroquímicos (usado no tratamento de doenças venéreas), veio possibilitar a resolução do puzzle da combustão e dar assim origem à química verdadeira.

As circunstâncias de cada protagonista eram diferentes. Isso nota-se até nos nomes com que cada um baptizou 0 "novo" gás: "eldsluft" (em sueco) ou
"Feuerluft" (em alemão), isto é, "ar de fogo", para Scheele; "ar deflogisticado", para Priestley; "ar vital", para Lavoisier. (Mais tarde, Lavoisier viria a baptizá-lo com o nome - errado - de oxigénio, que significa "gerador de ácidos".) A verdade é que três quartos do século XVIII (1700-75) são atravessados por uma construção admirável - mas errada que foi, de facto, o primeiro corpo de doutrina a sistematizar os mais variados conhecimentos químicos: a teoria do flogisto (a "matéria do fogo"), devida a Georg Stahl (1660-1734). Um bom exemplo de como o erro - um erro de longa duração - pode ser fundamental para o desenvolvimento da ciência. Stahl, professor de medicina e primeiro médico de Frederico, O Grande (da Prússia), dedicou-se principalmente ao estudo da combustão. A idéia era que por combustão as substâncias perdiam flogisto - o tal espírito ou matéria do fogo. Ora todos nós sabemos que a combustão - a oxidação em geral - não é uma perda, é um ganho; é uma combinação (com oxigénio) e não uma decomposição. A perda de flogisto é, afinal, um ganho de oxigénio. Não há massas negativas!

A oxidação é uma reacção envolvendo gases - oxigénio, sempre; dióxido de carbono, muitas vezes - difíceis de contabilizar. Só o uso sistemático da balança - e duma balança de precisão - poderia esclarecer o fenómeno. Foi esse 0 génio de Antoine Laurent Lavoisier, um químico que, no dizer do seu primeiro biógrafo, tinha a paixão das medidas. Para mais, as suas balanças, construídas por Fortin, eram obras-primas de precisão. Foram os trabalhos de Lavoisier que levaram à destruição da teoria do flogisto, e permitiram a unificação de fenómenos tão diversos como a combustão, o enferrujamento, a respiração dos animais. Pelo contrário, Priestley e Scheele morreram convencidos da perfeita validade do conceito de flogisto.

\section{O Julgamento de Paris}

Dois grandes químicos contemporâneos, Roald Hoffmann (químico teórico aplicado, professor da Universidade de Cornell, Prémio Nobel da Química, 
1981) e Carl Djerassi (professor da Universidade de Stanford, inventor da pílula contraceptiva e laureado com a Medalha Priestley) escreveram e publicaram recentemente uma peça em dois actos, "Oxygen", sobre um encontro ficticio entre os três putativos descobridores do oxigénio (e respectivas mulheres) em Estocolmo, 1777. Reinava então Gustavo III (1746-1792), grande patrono das ciências e das artes, que viria a ser assassinado num baile de máscaras na Ópera (Auber e Verdi composeram óperas sobre o assunto). Priestley, grande admirador da Revolução Francesa e Americana - viajou até Paris e conheceu Lavoisier; Scheele, que nunca saiu da Suécia, limitou-se a escrever a Lavoisier (sem nunca obter resposta).

O pretexto para a liberdade dramática do encontro dos três químicos do século XVIII é a "decisão" (também fictícia) da Academia Sueca de atribuir um Retro-Nobel da Química. (O Prémio Nobel não pode ser atribuído a título póstumo.) Um pequeno comité de quatro membros vai ter de decidir qual dos três foi quem primeiro descobriu - e percebeu o que descobriu - o oxigénio. $\mathrm{Na}$ altura do encontro fictício (1777), Lavoisier tinha 34 anos (a mulher, 19); Priestley tinha 44 (a mulher, 35) e Scheele 35 (Fru Pohl, 26; Scheele só casaria com ela dois dias antes de morrer). Enquanto os maridos discutiam ciência e repetiam experiências, as muIheres encontravam-se num sauna. A peça oscila entre os dois tempos: 1777 e a actualidade.

"Oxigénio" levanta a questão da prioridade da descoberta e do comportamento ético dos cientistas no que respeita à difusão de informação, problemas hoje tão actuais como o eram nos tempos de Lavoisier. Esse é o verdadeiro tema da peça de Hoffmann e Djerassi. Scheele foi indubitavelmente o primeiro a preparar o oxigénio (1771), mas os resultados só foram escritos em 1775 e publicados em 1777 ("Estudos químicos do ar e do fogo"); Priestley foi o primeiro a publicar (1774) e a comunicar pessoalmente a Lavoisier a sua descoberta; Lavoisier foi o primeiro a perceber o que aquilo significava, a intuir que o oxigénio não pre- cisava de ser preparado porque era um dos componentes do ar. 0 que é perturbante é que Lavoisier nunca citou os seus colegas, nem respondeu à carta de Scheele, escrita a 30 de Setembro de 1774 , onde este Ihe pedia para repetir a sua experiência.

"Oxygen" toma assim a forma dum moderno Julgamento de Paris, com Lavoisier, Priestley e Scheele nos papeis de Afrodite, Atenas e Hera. Ou, talvez meIhor, com Mme Lavoisier no papel de Afrodite, capaz de subornar os juizes com uma Helena de Tróia qualquer. O I

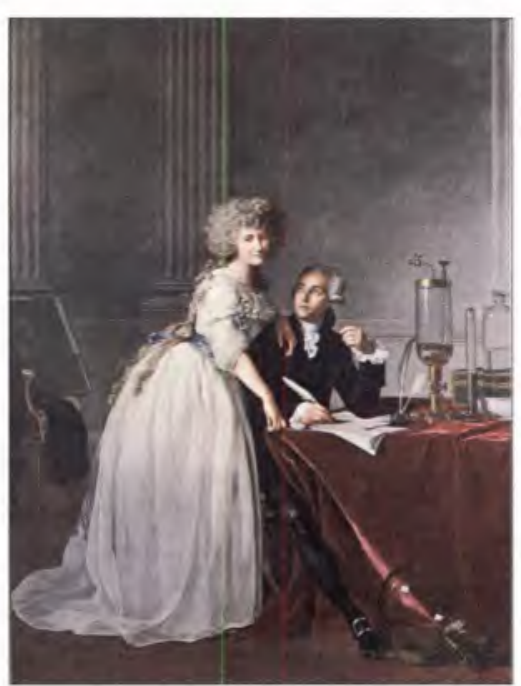

figura. 2 Jacques-Louis David, Lavoisier e sua Mulher (1789)

acto termina com uma "masque", "A Vitória do Ar Vital sobre o Flogisto", na qual Lavoisier e mulher destronam a velha teoria de Stahl, e o ll começa com os três químicos a realizar as experiências cruciais. A propósito: a peça trata ainda da matemática dos sistemas de votação.

O Julgamento de Paris (que deu origem à Guerra de Tróia) inspirou muitas pinturas, a mais célebre das quais é talvez - Paris e Helena, pintado por JacquesLouis David em 1788, por encomenda de irmão do rei (e futuro Carlos X), o Comte d' Artois. Como notou Anita Brookner, o quadro pode ter duas leituras: uma fortemente erótica, acentuada no primeiro plano pelas quatro bicas ejaculatórias na fonte rectangular; ou outra, mais clássica, reflexo do preceito de Winckelmann de que a verdadeira beleza “deve ser como a água límpida da nascente; quanto menos sabor tiver, mais saudável é". 0 exemplo não é escolhido por acaso. É que a pose do par Paris-Helena serviu de modelo quando, no ano seguinte, David pintou uma das suas obras-primas - o retrato de Lavoisier com a mulher, Marie Anne.

Aqui está o retrato dum cientista do século XVIII, de peruca polvilhada, redingote (sobrecasaca) de seda, bofes (peitilho) de renda e perna tão bem torneada como o globo de vidro que, em primeiro plano, mansamente repousa numa soga de crina de cavalo. Como era moda, a mulher, quinze anos mais nova, aparenta um ar mais desmazelado, com a capa e um portfólio de desenhos, abandonados num cadeirão na rectaguarda. Notar ainda as cores predominantes, de fortes conotaçōes políticas: vermelho, azul e branco e preto (Fig. 2). Marie Anne era prendada, tinha estudado pintura com David, e encarregara-se das ilustrações do famoso "Traité élémentaire de chimie" (1789) do marido. Era também uma das mulheres mais fascinantes do seu tempo, que despertou (e fruiu) muitas paixões. Benjamin Franklin ficou derretido com ela, $e$ há provas que teve um caso sério $e$ longo com Pierre Samuel Du Pont (pai do primeiro grande industrial americano, Eleuthère Irénée Du Pont, fundador da empresa com o mesmo nome). Marie Anne veio a casar, em segundas núpcias, com o Conde Rumford, o grande cientista-aventureiro, fundador da Royal Institution (e do enorme Jardim Inglês de Munique).

\section{O pai da revolução química}

Lavoisier começara a sua carreira na ciência aos 24 anos (como mineralogista), e aos 26 já era sócio efectivo da Academia das Ciências de Paris. Mas Lavoisier era mais do que um cientista era também um gestor, funcionário público e político (um pouco à semelhança dos ministros de educação portugueses...). Exercia a profissão de "Fermier Général" ou arrendatário do estado, isto é, era membro duma poderosa sociedade financeira que cobrava os impostos 


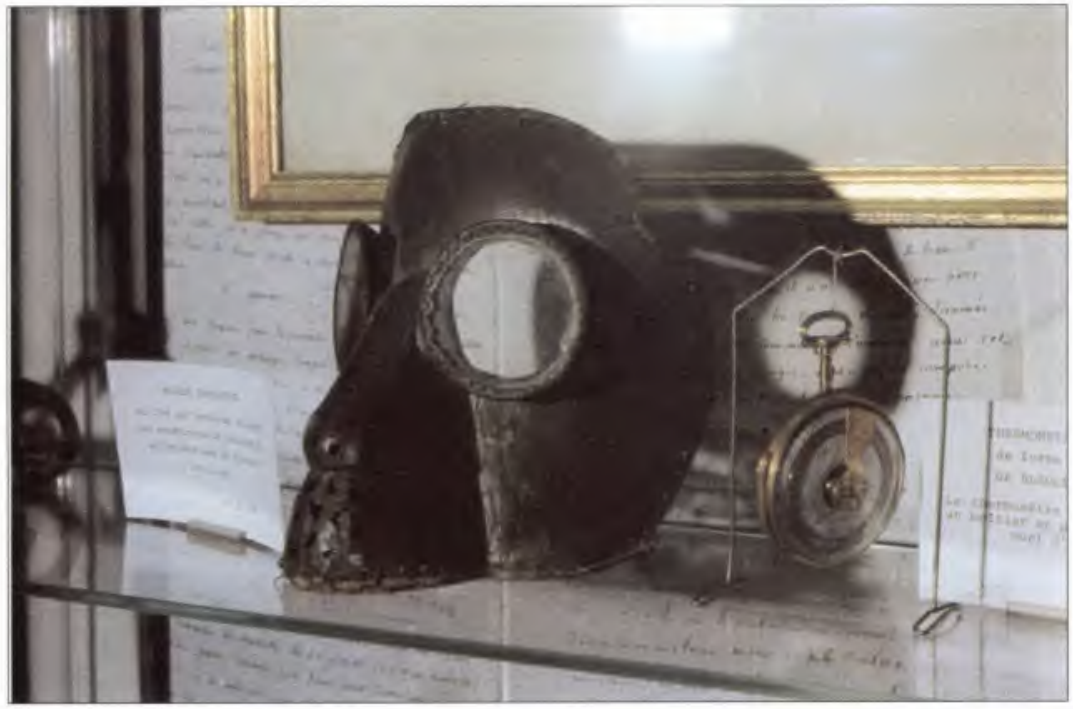

figura. 3 Máscara de protecção de Lavoisier

indirectos em nome do Rei (retendo uma generosa comissão). Esta experiência financeira em equilibrar as contas deve ter sido útil à formulação da primeira grande lei de conservação - a da massa. Não é por acaso que dinheiro e "massa" são sinónimos no imaginário popular!

Alem de "Fermier Général", Lavoisier desempenhava ainda as funções de "Régisseur des Poudres" ou Administrador Real das Pólvoras e Salitres. Não Ihe faltava trabalho. Passava as manhãs na "Ferme Génerale", e as tardes dividia-as entre a Academia e a Administração das Pólvoras. A química ficava para as horas vagas: das 6 às 9 da manhã e das 19 às 22. Mas não havia nada de amadorístico na sua relação com a química. Usava o melhor equipamento (frequentemente de grandes dimensões) no seu laboratório no Arsenal (da pólvora) e tomava os maiores cuidados no que respeita à segurança, como se pode verificar pela sua máscara de protecção (hoje no Museu Nacional de Técnicas, em Paris), Fig. 3.

Em 1771 Lavoisier casou com Marie Anne Pierrette Paulze, uma menina de 13 anos, filha dum "Fermier Général", acentuando-se assim a sua ligação à extremamente poderosa (mas corrupta e impopular) "Ferme Générale". Sabe-se, todavia, que sogro e genro exerceram a profissão com grande probidade, demonstrando, não raro, uma certa gene- rosidade para com os contribuintes mais pobres. A Régie das Pólvoras era igualmente detestada pelo povo, que via as suas terras escavadas e as propriedades destruídas, em nome dum direito central de recolha de terras salitrosas, essenciais ao fabrico da pólvora negra. Por outras palavras, o casal Lavoisier não era, propriamente, popular. Foram estas, talvez, as razões que levaram David a não apresentar o retrato duplo de M e Mme Lavoisier no Salon de Pintura de 1789 .

Ao contrário de Priestley, que era cientificamente conservador mas politicamente revolucionário (Edmund Burke chamava-Ihe, apropriadamente, o "gás selvagem"), Lavoisier, que revolucionou a química, era politicamente conservador. No segundo aniversário da queda da Bastilha (14 de Julho de 1791), uma multidão enfurecida com as ideias progressistas de Priestley incendiou-lhe a casa, laboratório e igreja em Birmingham. (A seu tempo, Priestley emigraria para a América.) Lavoisier ainda se entusiasmou com os novos ideais de liberdade. Foi eleito deputado à Assembleia Comunal em representação dum dos bairros de Paris, e chegou a ser convidado (1792) por Luís XVI para Ministro das Contribuições Públicas. (Não aceitou.) Entretanto tinha participado, a pedido da Assembleia Nacional, na comissão que estabeleeu o novo sistema de pesos e medidas (1790). Coube-lhe estudar as melhores ligas para construir o metro-padrão. Fez também parte da Comissão Consultiva das Artes e Ofícios, criada pela Assembleia Nacional, tendo aí defendido uma instrução primária universal e gratuita.

Foram o ódio generalizado aos "fermiers généraux" e uma certa arrogância cientifica que deitaram Lavoisier a perder. Não tolerava arrivistas, muito menos os ignorantes. Jean-Paul Marat (1743-93), seu exacto contemporâneo, tornou-se célebre como jornalista e agitador virulento. Era também médico de renome (exercera a profissão em Londres, recebera um grau de doutor honoris causa em medicina pela Universidade de St Andrews), com pretensões a químico e ansiava entrar na Academia das Ciências. Lavoisier, com quem travou várias polémicas científicas, vetou-o sistematicamente. Tanto bastou para arranjar um inimigo figadal.

Para Marat, os sábios e cientistas constituiam uma aristocracia (ou um clero) a destruir. "Os académicos são os cónegos das ciências, das literaturas e das artes", escreveu. Em 1793 a Convenção suprimia todas as Academias. Entretanto tinham começado as perseguições aos arrendatários do estado. Tal como seu sogro e mais de uma vintena de outros rendeiros, Lavoisier foi preso, sumariamente julgado e condenado à morte pela guilhotina. Foi a quarta vítima nesse desventurado dia 8 de Maio de 1794. Na véspera de morrer, escreveu: "Nem o exercício de todas as virtudes sociais, nem serviços prestados à pátria, nem uma carreira utilmente dedicada ao progresso das artes e conhecimentos humanos, bastam para evitar um fim sinistro e morrer como culpado". Entre as provas de culpa (traição), estavam as cartas que trocara com Priestley, Black e o industrial Josiah Wedgwood. Ninguém se dera ao trabalho de as traduzir! A excepção da mulher, poucos ou nenhuns 0 defenderam, e muitos 0 atacaram, mesmo colegas académicos e discípulos como Gaspard Monge (1746-1818), o inventor da Geometria Descritiva, e o químico (e vira-casacas) Fourcroy (1755-1809). Coube a Lagrange proferir, mais tarde, o epitáfio perfeito: "Bastou-Ihes um momento para 
fazer cair esta cabeça e cem anos talvez não cheguem para produzir outra igual". Parafraseando o "Romeu e Julieta" de Shakespeare, "não há história de maior desventura do que esta" de Lavoisier.

\section{O Amigo do Povo}

Foi Goethe quem mostrou que as relações pessoais são como as reacções químicas - combinaçōes de átomos que se fazem e desfazem. É tudo uma questão de "afinidades electivas". David, o casal Lavoisier e Marat formam, deste ponto de vista, um quarteto interessante. David, mestre de Marie Anne e pintor do casal; David apoiante de Marat (ambos tinham os seus diferendos com as Academias); Marat inimigo de Lavoisier.

Jacobino, Marat teve uma vida agitada, interpolada por exílios vários. Nos tempos do Terror, foi o terrorista número um. O seu veículo era o jornal Ami du Peuple (1788-92), que usou frequentemente para insultar e denunciar Lavoisier, a quem chegou a chamar "corifeu dos charlatães". Num panfleto publicado em 1790, Marat dirigiu-se ao povo, apelando à violência generalizada: “500 ou 600 cabeças cortadas assegurar-vosiam tranquilidade, liberdade e felicidade. Um humanitarismo falso atou-vos os braços e suspendeu os vossos socos. Custar-vos-á as vidas de milhões dos vosso irmãos". Não lhe serviu de muito. Nas eleições de 1791 apenas teve dois votos!

Talvez em consequência de longos períodos na clandestinidade e passagem por abrigos insalubres, Marat contraiu uma medonha doença de pele, caracterizada por pústulas supurantes. Para alívio, recorria a frequentes banhos tépidos de imersão. Foi numa dessas ocasiōes que veio a ser assassinado por Charlotte Corday, uma Girondina. O corpo foi imediatamente embalsamado e exposto em câmara ardente num estrado, por cima da banheira e do caixote que servia de secretária. David pintou 0 amigo moribundo naquela que é, talvez, a sua pintura mais religiosa (Fig. 4). (Por coincidência, Marat fora médico das tropas do Conde d' Artois, o mesmo que encomendara o quadro de Paris e
Helena a David.) A pose sugere uma "Pietà", ou melhor, a cena do sepulcro. Ai está Marat de pena na mão, turbante ensopado em vinagre, protegido por um lençol (para evitar o contacto das lesões de pele com o cobre da banheira). $\mathrm{Na}$ mão, a carta que Corday Ihe entregara com os nomes de pretensos inimigos; em primeiro plano, em cima do caixotesecretária, uma admirável e chardinesca natureza morta com pena, tinteiro e papel. Quando David apresentou o quadro à Convenção, propôs que Marat fosse sepultado no Panteão.

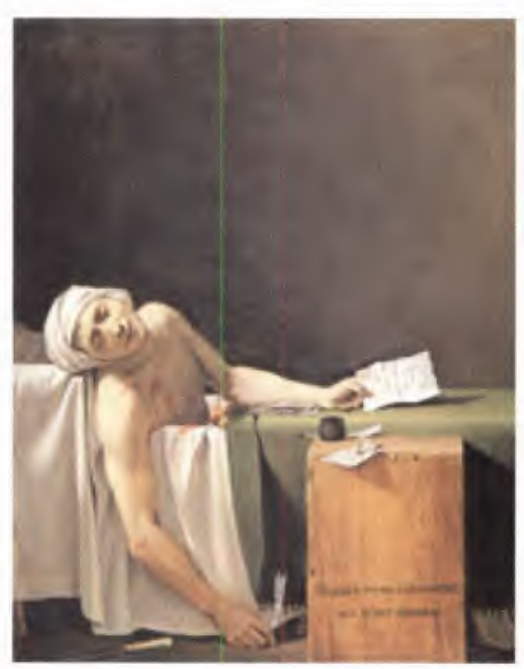

figura. 4 Jacques-Louis David, Marat assassinado (1793)

\section{O químico músico}

Lavoisier não foi o único grande cientista a dividir o tempo entre a química e outros afazeres. Na Rússia de Dostoievski e Mendeleev, houve um quimico que é hoje injustamente mais conhecido como compositor do que como químico orgânico: Aleksandr Porfir'evitch Borodin (1833-1887). Começo com um apontamento pesoal. Há meses, ao remexer numa velha arca, fui descobrir uma verdadeira cápsula do tempo: um documento escrito por mim aos dez anos em que declarava para a posteridade que a minha peça de música favorita era o poema sinfónico de Borodin, Nas Estepes da Ásia Central (1880). E acrescentava, para que não restassem dúvidas, que tinha a certeza que essa predilecção permaneceria para o resto da minha vida!
Não me recordo qual era a fase que eu então atravessava, no que respeita à profissão a escolher (a resposta à estafada pergunta de "O que é que quero ser quando for grande?"). Certamente já tinha ultrapassado a ambição de ser pastor de ovelhas, possivelmente também a de ser médico (então, como hoje, desmaiava se via sangue...); devia andar na fase de querer ser astrónomo. Hoje leio a minha devoção a Borodin como uma premonição da minha queda para químico.

Há três vectores fundamentais na vida $\mathrm{e}$ carreira de Borodin: a música, a química e a educação feminina, em particular o acesso das mulheres aos estudos universitários. Eram actividades distintas que ele levava muito a sério, sem perder tempo. Como escreveu, "Nós, os pecadores, rodopiamos, como sempre, num redemoinho quotidiano de azáfamas oficiais, académicas, científicas e artísticas. Corremos para todo o lado e nunca temos tempo: o tempo voa como uma locomotiva a alta velocidade".

Borodin fez parte daquela elite de químicos que, em circunstãncias particularmente adversas, colocaram a ciência russa no panorama internacional. Químicos como Nikolai Zinin, Dmitri Mendeleev, Nikolai Menshutkin, Valdimir Markovnikov, Aleksandr Butlerov, etc. Embora filho ilegítimo (Borodin era o apelido do mordomo do pai), teve uma educação primorosa e cedo mostrou notável talento musical. 0 seu instrumento era o violoncelo, mas tocava também piano e flauta. Falava alemão, francês, inglês e italiano. Aos 9 anos compôs uma polka, Hélène apaixonada, e aos 14, um complexo concerto para flauta e piano. Pintava aguarelas, fazia esculturas de pasta de papel e, ainda adolescente, começou a interessar-se por química. Uma das suas curiosidades era perceber porque é que uma substância cristalina branca - para um jóvem, o cúmulo da estabilidade - podia explodir. A mãe deixou-o montar um laboratório em casa e espalhar retortas por todo o lado; ao entrar, as visitas notavam logo o cheiro a produtos químicos.

Aos 17 anos entrou para a Academia Medico-Cirúrgica de São Petersburgo, 
que viria a ser a sua casa para toda a vida (fig, 5). Foi o melhor aluno do curso, mas rejeitou uma carreira de médico (desmaiava se via sangue, e contraiu uma perigosa infecção ao dissecar um cadáver) em favor da química. Contribuiu o facto de ter sido aluno do grande químico orgânico Nikolai Zinin, que se celebrizara com a sintese da anilina. Facto inédito na escola, Borodin começou a trabalhar com Zinin ainda antes de acabar o curso. A sua tese doutoral (1858) foi "Sobre a analogia entre o ácido arsénico e o ácido fosfórico no comportamento químico e toxicológico". Pela primeira vez na história da Academia, uma dissertação fora escrita e publicamente discutida em russo.

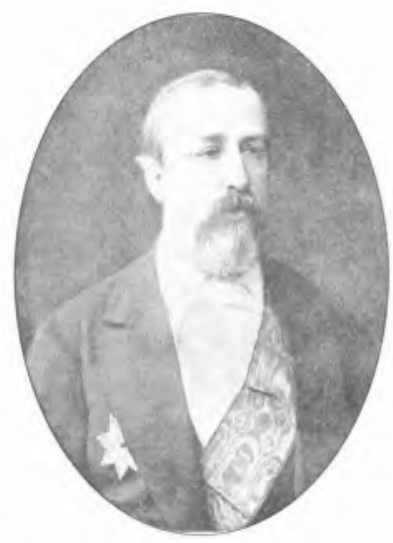

figura. 5 A. P. Borodin

Embora fosse profundamente nacionalista, Borodin nunca hesitou em estabelecer contactos (científicos e musicais) com o estrangeiro. Em 1857 foi ao Congresso Internacional de Oftalmologistas em Bruxelas, e aproveitou para prolongar a viagem até Paris para visitar o laboratório de Berthelot. Como bolseiro da Academia passou três anos (1859-62) no estrangeiro - a maior parte do tempo em Heidelberg, no laboratório de Emil Erlenmeyer (onde estudou os derivados da benzidina), mas também em Paris (derivados bromados dos ácidos carboxilicos) e em Pisa (fluorinação de compostos orgânicos).

Heidelberg era então uma meca para os químicos russos. Mendeleev (18341907), por exemplo, tinha ido para lá para trabalhar com Robert Bunsen, mas ao verificar que pouco poderia aprender (achava os estudantes alemães pouco motivados), resolveu montar um laboratório em casa e prosseguir investigação independente. Borodin visitou-o logo no dia de chegada a Heidelberg. Ficaram grandes amigos (fig. 6) e viriam a viajar juntos pela Europa. Mendeleev contaria mais tarde como ele e Borodin foram até Itália apenas com uma pequena maleta de mão para os dois (para não dar nas vistas), e como resolveram vestir blusas para parecerem artistas, "o que trazia muitas vantagens em Itália". No auge da fama, Mendeleev costumava dizer que nas suas viagens ao estrangeiro a primeira coisa que lhe pediam eram noticias sobre as últimas investigações de Borodin.

Borodin publicou oito trabalhos durante os três anos no estrangeiro. Em 1860, juntamente com Zinin e Mendeleev, participou no célebre Congresso Internacional de Quimica em Karlsruhe. Foi ai que Stanislao Cannizzaro (18261910) destruiu a Teoria Dualistica de Berzelius, provando a superioridade da Teoria Unitária de Gerhardt e Laurent. Cada substância deve ser considerada como uma entidade própria, sujeita às regras da substituição de átomos. De regresso à Rússia em 1862, Borodin foi logo nomeado professor assistente de química da Academia Medico-Cirúrgica, passando a professor catedrático em 1864. É então que inicia os seus trabaIhos sobre a condensação de aldeídos, que o levaram à descoberta da função aldol. São particularmente notáveis as suas investigaçōes sobre o valeraldeido, $\mathrm{C}_{4} \mathrm{H}_{9} \mathrm{CHO}$, que conduziram à descoberta dum novo ácido gordo, o ácido "isocáprico" (8-metilnonanóico), $\left(\mathrm{CH}_{3}\right)_{2} \mathrm{CH}$ $\left(\mathrm{CH}_{2}\right)_{6} \mathrm{COOH}$.

Uma boa parte dos seus estudos sobre a condensação de aldeídos foi retomada por August Kékulé (1829-96), com quem Borodin teve uma polémica por questōes de prioridade. De igual modo, a sua descoberta do aldol colidiu com investigações paralelas de Charles-Adolphe Wurtz (1817-84). Borodin publicava não apenas em revistas russas, mas também em revistas alemãs e francesas (em forma resumida ou desenvolvida), para tornar conhecidas as suas investigações. Mesmo assim, era um realista; ao aperceber-se que nunca poderia competir com os recursos (laboratoriais e humanos) de Wurtz, abandonou os seus trabalhos sobre o aldol.

No princípio da sua carreira Borodin tinha sido alertado por Zinin para o facto de não se poderem "caçar duas lebres ao mesmo tempo". Borodin considerava-se um químico profissional e apenas um "compositor de Domingo". A música era para as horas vagas. Em 1862 conheceu o composior e virtuoso do piano Mily Balakirev (1837-1910), à volta do qual se começara a formar um grupo de jovens e talentosos compositores, segui-

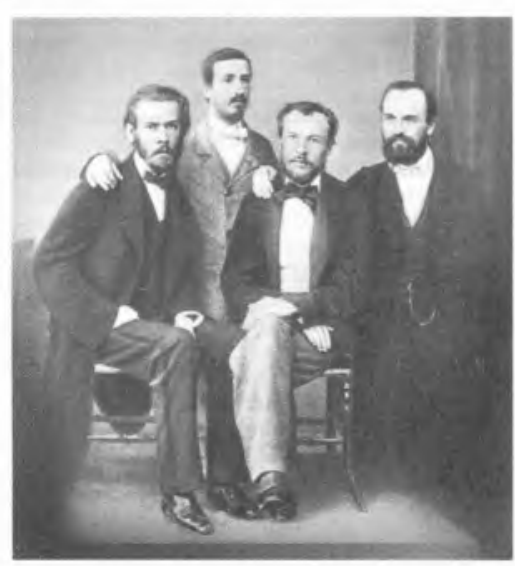

figura. 6 Membros do Circulo de Heidelberg: Zhitinskii, Borodin, Mendeleev, Olevinskii

dores da música nacionalista de Mikhail Glinka (1804-57): Cesar Cui (18351918), Nikolai Rimsky-Korsakov (18441908) e o já amigo de Borodin, Modest Mussorgsky (1839-81). O crítico musical Vladimir Stassov chamou-lhes (1867) "Moguchaia Kuchka" (Pequeno Mas Poderoso Grupo) conhecido, no resto da Europa, por Grupo dos Cinco.

O tempo livre podia escassear, mas Borodin tomava o seu passatempo muito a sério. Nas idas a congressos de química no estrangeiro aproveitava para contactar compositores. Franz Liszt (1811-86), que visitou por três vezes em Weimar, e a quem dedicou Nas Estepes da Ásia Central, foi um dos seus apoiantes; Liszt admirava, em particular, a originalidade das duas sinfonias. De saúde débil, Bo- 
rodin aproveitava para compor quando a doença o retinha em casa. "Quando estou muito doente, fico em casa; quando não posso fazer nada eficientemente, quando me dói a cabeça, e os olhos estão inflamados, quando tenho de procurar o lenço no bolso de dois em dois minutos - então escrevo música". Resultado: os amigos - e não só os do círculo musical - chegavam a desejar que ele adoecesse para poder compor. Mesmo à bancada do laboratório estava sempre a cantarolar.

\section{A educação das mulheres}

Não menos notável foi a acção desenvolvida por Borodin em prol da educação feminina e do acesso das mulheres aos estudos terciários. Como no resto da Europa, também na Rússia era vedado às raparigas frequentar as universidades; quando muito podiam assistir a algumas lições abertas ao público em geral. Borodin lutou activamente por alterar esta situaçẩo, conseguindo finalmente em 1872 que fossem criados cursos só para mulheres na sua Escola Medico-Cirúrgica. Foram os primeiros cursos universitários femininos no mundo. Teve a seu favor os argumentos da elevada mortalidade infantil e de epidemias frequentes. Mesmo assim, os cursos eram nominalmente de Obstetricia, estando todos os outros vedados às mulheres. Particularmente, Borodin encarregou-se de oferecer disciplinas de cultura e ciências fundamentais, e também não hesitou em chamar as estudantes mais talentosas para o seu laboratório e de Ihes dar co-autoria nos trabalhos publicados. Eram todas decisōes revolucionárias, à época.

São desta altura os seus estudos dos derivados iodados do fenol, bem como as pesquisas sobre a conversão do azoto nos organismos vivos. Deve-se a Borodin o estabelecimento (1876) dum método de dosagem da ureia no sangue (ataque da urina com soda cáustica e bromo e medição do volume de azoto libertado), que viria a ser conhecido como método de Ambard (1920).

Borodin era um homem corajoso e académico empenhado. Teve papel impor- tante na fundação da Sociedade Russa de Química, tentou que Mendeleev fosse nomeado professor de física da Academia Medico-Cirúrgica, e protestou publicamente quando Mendeleev foi vetado pela Acadernia de Ciências. O "establishment" da ciência russa era profundamente conservador e perseguia os cientistas mais activos e inovadores. Os anos 1880 s foram particularmente dificeis. A instabilidade política seguiu-se a repressāo universitária. Os professores passaram a ser nomeados pelo governo (em vez de serem escolhidos pelas escolas dentro dum regime de autonomia). A admissão das mulheres à universidade terminou em 1882. A investigação passou a ser olhada com desconfiança, como se fosse uma actividade subversiva. Cortes financeiros impediam a renovaçāo do equipamento ou a compra de consumiveis. Até o gás foi cortado. Nos últimos anos de vida (1880-87) Borodin não publicou praticamente nenhurn artigo científico. Mais uma desventura química.

Entretanto dedicava-se à composiçāo da sua ópera épica, Príncipe Igor (que deixaria incompleta). Morreu, de ataque cardiaco, durante uma festa da faculdade. Tinha 53 anos. Foi sepultado no cemitério do Mosteiro de Aleksandr Nevski, ao lado de Mussorgsky. Apropriadamente, o túmulo foi decorado com uma mistura de fórmulas químicas e de compassos das suas composições mais célebres. Rimsky-Korsakov e Aleksandr Glazunov (1865-1936) encarregaram-se da edição do espólio musical. Foram eles que terminaram a partitura da ópera com base nos esboços encontrados (e do que tinham ouvido Borodin tocar ao piano), bem como de duas partes da $3 .^{a}$ Sinfonia. 0 exame detalhado das partituras de Borodin inspirou Rimsky-Korsakov a compor o seu célebre poema sinfónico Schéherazade (1888).

\section{A mulher esquecida}

Nos tempos em que Lise Meitner (18781968) cresceu e estudou em Viena, as únicas mulheres que entravam na universidade eram as da limpeza. Nem sequer podia fazer o liceu que dava acesso ao ensino superior - os chamados preparatórios. A lei só foi mudada em 1899, já Lise tinha atingido a maioridade. Determinada a seguir uma carreira nas ciências físicas, Meitner fez os oito anos do secundário em dois e entrou na universidade em 1901. Tinha 23 anos!

Mulher pioneira, teve de enfrentar a discriminaçāo toda a vida. 0 seu consolo era a música - principalmente as cançōes de Brahms, que cantava acompanhando-se ao piano. Na universidade teve a sorte de ser aluna de Ludwig Boltzmann (1844-1906), um professor de temperamento emocional, capaz de galvanizar os alunos. Lise Meitner, estudante madura, não perdeu tempo: em 1905 estava doutorada em física. No princípio do século, não era fácil a uma mulher prosseguir uma carreira de investigação cientifica, muito menos fazer um percurso académico. As hipóteses não eram muitas: Marie Curie (18671934) rejeitou-a; Max Planck (18581947), pelo contrário, arranjou-lhe um lugar em Berlim. A vocação de Meitner era, porém, experimental. Aconteceu que Otto Hahn (1879-1968), recémchegado do laboratório de Ernest Rutherford (1871-1937) em Cambridge, e já a trabalhar no Instituto Químico de Berlim do Professor Emil Fischer (1852. 1919), procurava um colaborador. Fischer, que tinha ganho o Prémio Nobel da Química em 1902 graças ao seu trabalho sobre os açúcares, recusava-se, porém, a empregar mulheres no seu Instituto. Foi só depois da intercessão de Rutherford que Fischer autorizou a entrada de Lise Meitner.

A história é incrivel e merece ser contada e recontada. O laboratório atribuído a Meitner era uma antiga oficina de carpintaria na cave do edifício, com entrada própria. Estava-Ihe vedado o acesso ao resto do instituto. Para ir à retrete tinha de sair à rua e andar dois quarteirões até um hotel próximo. (Só em 1908 foi instalado um lavabo para senhoras no Instituto.) Hahn tinha o seu laboratório num andar superior que era, portanto, inacessivel à sua colaboradora. Para discutir os trabalhos, Meitner tinha de esperar que Hahn a visitasse na cave; as experiências eram planeadas sem ela poder observar o equipamento ou verifi- 
car como as coisas funcionavam. Mesmo assim, Meitner conseguiu frequentar algumas aulas e ouvir seminários graças a um estratagema: esconder-se por debaixo dos degraus do anfiteatro!

Gradualmente as condições melhoraram e foram-se abrindo portas às muIheres. Em 1912 Hahn e Meitner mudaram-se para o departamento de radioquímica do recém-criado Instituto do Kaiser Wilhelm (mais tarde conhecido como Instituto Max Planck). Em 1926 Lise Meitner tornou-se na primeira mulher professora de fisica em toda a Alemanha. Tinha 48 anos. A parceria Meitner-Hahn foi uma das mais bem sucedidas da história da ciência. De certo modo, os dois completavam-se - Hahn, o homem espontâneo e intuitivo, mais químico que físico; Meitner, a mulher crítica e racional, mais física que química. As suas contribuiçōes mais importantes foram a descoberta do protactínio e da fissão nuclear.

Nos anos 1930s uma das linhas de investigação mais populares em física nuclear era a produção de elementos transuranianos. Enrico Fermi (1901-54) em Itália, Irène Joliot-Curie (1897-1956) em Paris e Hahn e Meitner em Berlim, todos tentaram produzir núcleos mais pesados bombardeando o urânio com neutrões. Os resultados, porém, eram esquisitos e pouco reprodutiveis. Tratava-se dum caso exemplar de mentes toldadas por idéias preconcebidas. Como nāo estavam à espera daquilo que realmente acontecia - a fissão nuclear não a encontraram imediatamente (embora houvesse indícios de formaçāo de bário ou mesmo lantânio, ambos átomos mais pequenos que 0 urânio). Foi realmente Meitner quem percebeu o que estava a acontecer, mas nessa altura já ela estava a centenas de milhas de distância de Berlim. De facto, a 13 de Julho de 1938, a judia Lise Meitner fugia da Alemanha e do nazismo, deixando ficar no laboratório de Berlim para não levantar suspeitas - toda a sua documentação científica.

Após curtas passagens pela Holanda e Dinamarca, Meitner acabou por se estabelecer em Estocolmo, no laboratório de
Kai Manne Siegbahn, o construtor do primeiro ciclotrão europeu (e que viria a receber o Prémio Nobel da Física em 1981). Otto Hahn fora também galardoado com o Prémio Nobel da Química em 1944 (atribuido só em 1945), "pela sua decoberta da fissão dos núcleos pesados". Lise Meitner, mulher, foi completamente ignorada.

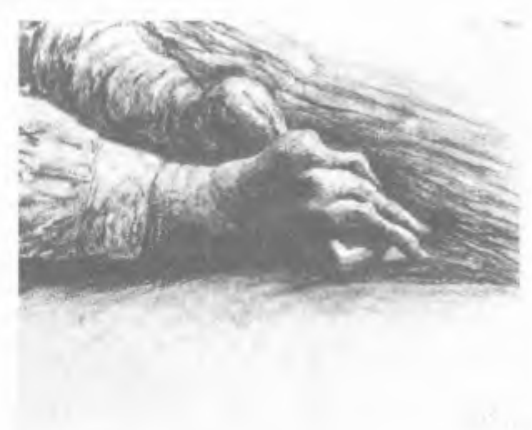

figura. 7 Henry Moore, Desenho das mãos de Dorothy Hodgkin (1978)

\section{As mãos de Dorothy}

Quando, em 1966, cheguei a Oxford para preparar o doutoramento no Inorganic Chemistry Laboratory, havia uma famosa inquilina no rés-do chão (o meu laboratório era no $1 .^{\circ}$ andar, o primeiro à direita ao virar da escada). Sozinha, Dorothy Crowfoot Hodgkin (1910-94) ganhara em 1964 o Prémio Nobel da Química pela sua descoberta, usando a difracção de raios- $X$, das estruturas do colesterol, penicilina, vitamina B12 e insulina. Era uma modesta mulher de sorriso doce, admirada e amada por todos. Lembro-me do meu supervisor e querido mestre, Lionel Staveley (1914-1996) me dizer que, na sua experiência, a atribuição do Nobel a Hodgkin seria o único caso em que tal galardão não suscitara controvérsia ou inveja. Por outras palavras, toda a comunidade cientifica reconhecera que ela merecera o Nobel e merecera-o sozinha!

Quando a conheci, era uma mulher precocemente envelhecida, de cabelo grisalho e mãos muito deformadas. Julgava eu que tal se devia a uma longa vida de exposição aos raios-X. Só mais tarde vim a saber que Dorothy tinha sido vitima, aos 24 anos, duma artrite reumatóide aguda que the deformara o carpo e metacarpo e transformara as articulações dos dedos em enormes nódulos protuberantes. 0 escultor Henry Moore (1898-1986) viria a fazer (1978) um belo desenho das mãos de Hodgkin que ela considerava como o seu melhor retrato - fig. 7! (Talvez porque o seu trabalho dependia muito da destreza de mãos.) Pois bem, apesar destas dificuldades, contava-se que Hodgkin nunca tinha deixado cair um cristal!

Dorothy Crowfoot sempre soube que queria ser química e muito cedo começou a interessar-se por e a coleccionar cristais - nessa altura um passatempo feminino muito comum. Adolescente, montou um laboratório no sótão de sua casa (tal como Borodin), e aos 16 anos recebeu de presente um livro sobre cristais, escrito por William Bragg (18621942), para jovens. (Bragg recebera o Prémio Nobel da Física em 1915, precisamente pelos seus estudos da estrutura cristalina por difracção de raios-X.) Dorothy formou-se em química em Oxford, e passou depois dois anos em Cambridge (1932-4), a trabalhar com o famoso John Desmond “J. D." Bernal, especialista de estruturas. JD tinha a alcunha de "Sage" porque sabia muito de muitos assuntos. Dele se dizia também que era pálido por fora mas vermelho por dentro (era membro do partido comunista). Era também um homem com uma complicadíssima vida sentimental: casado, tinha duas amantes por conta ("teúdas e manteúdas", como diria Fernão Lopes) e alimentava ainda uma série de casos extra-maritais.

A influência - cientifica e política - de J. D. em Dorothy Crowfoot foi enorme. Foi, toda a vida, uma mulher de esquerda, directamente envolvida em causas pacifistas (mas nunca discutia politica com os alunos!). Em 1937 casou com Thomas Hodgkin, um historiador que tinha aderido ao partido comunista. Se os seus primeiros artigos científicos tinham sido escritos por Dorothy Crowfoot, agora passou a assiná-los como Dorothy Hodgkin. Levou tempo até que a comunidade cientifica percebesse que a Dorothy que tinha investigado a estrutura da penicilina era a mesma que tinha descoberto a estrutura da vitamina B12! 
Em 1934 voltou para Oxford, como "fellow" de química do Sommerville College. Sommerville era, e continuou a ser durante cerca de quatro décadas, um colégio só para mulheres (tal como muitos outros eram só para homens). Até o clube de química da universidade era só para homens (embora o dos estudantes, o famoso Alembic Club, admitisse muIheres). Em Oxford, colégios e universidade são, de certo modo, instituições independentes (embora só se possa ser membro da universidade através dum colégio). Dorothy ensinava (sistema tutorial) em Sommerville, mas fazia a investigção num laboratório da universidade. Sendo mulher, foi parar à cave do University Museum, um edificio neo-gótico em Parks Road, muito admirado por John Ruskin (1819-1900), o controverso artista e crítico que fora professor Slade de Belas-Artes em Oxford.

Margaret Thatcher foi sua aluna, e as duas ficaram amigas para a vida. A nós, portugueses, habituados à promiscuidade do pessoal com o profissional e de ambos com o político, pode parecer extraordinário que duas mulheres, situadas cada uma em seu extremo do espectro político, se entendessem tão bem. A verdade é que as duas gostavam muito uma da outra. Mesmo quando chegou a primeiro-ministro, Thatcher continuou a convidar os Hodgkins para fins-de-semana em Chequers. Diz-se que foi Dorothy que convenceu Thatcher a encetar contactos com Mikhail Gorbachov, mesmo antes de este ascender a Secretário-Geral do Partido Comunista da União Soviética, e assim começar uma relação política que teve enormes consequências no redesenhar do mapa da Europa.

\section{Coda}

Há ainda aqueles que transformaram as suas fraquezas, desventuras e horrores em forças. Um exemplo maior é o do químico industrial Primo Levi (1919-87), que sobreviveu a Auschwitz. Foi esta tragédia que fez dele um escritor, dos maiores da literatura italiana do século passado. "Se questo è un uomo" (1948) é o comovente testemunho dessa experiência e de como é possivel passar das trevas à luz (Nelson Mandela viria a percorrer caminho semelhante). A sua modéstia e reticência eram proverbiais. Um dia, um químico jugoslavo de visita à fábrica perguntou-lhe se ele era o autor dum livro célebre. Levi não se desmanchou e respondeu: "Há um Primo Levi que escreveu um livro famoso e também é pintor; talvez se esteja a referir a ele."

A vida dum químico na fábrica é uma ratoeira de desastres potenciais. Levi viveu obcecado por explosões, incêndios e outros perigos químicos, e incorporou-os na sua ficção (quase sempre autobiográfica). Na sua obra-prima mais conhecida, "II sistema periodico" (1975), três dos capitulos tratam destes desastres: 0 do Hidrogénio acaba com uma explosão, o do Potássio num incêndio, e o do Enxofre constrói-se à volta de fogo e explosão. Muita da sua experiência fabril na SIVA (ou Società Industriale Vernici Affini, uma firma dedicada à produção de vernizes e resinas), desastres incluídos, foi incorporada em "La chiave a stella" (1978). Foi na SIVA que Levi desenvolveu o PVF (polivinilformal), a base da fortuna da empresa. Quando se reformou em 1977, ofereceram-Ihe uma colecção de tubos de ensaio com todas as resinas e vernizes isolantes produzidos pela firma - um dos tubos vinha todo rachado, com o conteúdo negro e carbonizado, lembrança viva duma explosāo!

Levi criava literatura com os materiais mais comuns. Uma das suas histórias mais apreciadas, "Stabile/Instabile", diz respeito à madeira. $\mathrm{O}$ autor e cientista vêa como um material forte e leve, mas de grande instabilicade quimica. "A madeira está ansiosa por se oxidar”, escreve. E assim voltamos ao princípio deste artigo, ao papèl do oxigénio na combustão...

O professor de química é, por natureza, um simplificador que valoriza a simetria e a ordem. Gosta de lembrar que a molécula do metano forma um tetraedro perfeito, que os electrões deslocalizados do benzeno desenham um hexágono regular, que a baixa pressão um gás obedece à equação dos gases perfeitos, que a massa se conserva (muito útil no acerto de equações). No entanto, a realidade - isto é, a vida - é complexa, assimétrica e caótica. A visão simplificada imposta pelo modelo e pela teoria é quase sempre, uma mentira. Para o docente, o problema está em tornar toda esta complexidade pedagogicamente acessivel. Sugiro que a solução está na narrativa, na velha tradição oral das grandes culturas. Um sábio chega a um povoado e conta uma história - assim começa o teatro. Tanto o sábio como a audiência podem ser analfabetos. Pouco importa. As histórias encadeiam umas nas outras, à semelhança das d'"As Mil e Uma Noites" e o resultado é magia. A química - toda a ciência - é igualmente mágica.

Executamos uma experiência; analisamos os resultados; avançamos com hipóteses; construímos conjecturas; tecemos teorias; procuramos provar que as teorias estão erradas para descobrirmos outras melhores. Pelo caminho vamos lembrando as desventuras do passado $e$ contando histórias. Querem aprender química? Sim, Eu Conto (que é o título dum livro bonito que eu li quando andava na Escola Primária).

\section{Bibliografia}

As Comemorações do Segundo Centenário de Lavoisier, Academia das Ciências de Lisboa, Lisboa, 1944

Anita Brookner, Jacques-Louis David, Harpe \& Row, New York, 1980

Carl Djerassi e Roald Hoffmann, Oxygen, Wiley-VCH, Weinheim, 2001.

N. A. Figurovskii e Yu. I. Solov'ev, Aleksandr Porfir'evich Borodin - A Chemist's Biography, Springer-Verlag, Berlin, 1988.

Sharon Bertsch McGrayne, Nobel Prize Women in Science, Birch Lane Press, New York, 1993.

Georgina Ferry, Dorothy Hodgkin - A Life, Granta Books, London, 1998.

Carole Angier, The Double Bond: Primo Levi - A Biography, Viking, London 2002. 